\title{
Produtividade e teor de nutrientes do milho em consórcio com braquiária
}

\author{
Nutritional efficiency of maize in intercropping with signalgrass
}

\author{
Daniel Valadão Silva ${ }^{I}$ Gustavo Antônio Mendes Pereira ${ }^{I I^{*}}$ Marco Antônio Moreira de Freitas ${ }^{\text {III }}$ \\ Antonio Alberto da SilvaII Tocio Sediyama ${ }^{I I}$ Gustavo Soares Silva ${ }^{\text {II }}$ \\ Lino Roberto FerreiraII Paulo Roberto Cecon ${ }^{\text {IV }}$
}

\section{RESUMO}

Nos cultivos consorciados, a competição entre as espécies pelos recursos do meio pode inviabilizar o sistema. A intensidade da interferência de uma espécie sobre a outra, resultante dessa competição, depende da densidade populacional das espécies componentes do sistema. Na busca de melhor entendimento desses efeitos, avaliaram-se os efeitos de densidades de $\boldsymbol{U}$. brizantha sobre o crescimento da forrageira e a eficiencia nutricional e produtividade do milho em sistema consorciado. Os tratamentos foram casualizados em blocos com quatro repetições. O milho DHB 390 RR foi semeado no espaçamento de 0,50m e na população de 60000 plantas $h a^{-1}$, sendo o plantio da braquiária realizado manualmente na linha de plantio. As avaliações nutricionais foram realizadas aos 60 dias após o plantio das espécies (DAP) e a produtividade de grãos do milho e a matéria seca da braquiária foi mensurada aos 160 DAP. A matéria seca da braquiária apresentou comportamento quadrático com o aumento da densidade de plantio. O aumento da densidade da U. brizantha resultou em redução linear dos teores de nitrogênio, fósforo, cálcio e magnésio em plantas de milho, no entanto, sem alterar os teores de potássio e enxofre. A produtividade de grãos foi afetada negativamente em densidade de braquiária superior a 15 plantas $m^{-2}$. Conclui-se que a interferência da U. brizantha sobre o milho, em plantio simultâneo, reduz os teores de fósforo, cálcio e magnésio, independente da densidade de plantas. A produtividade de grãos e o teor de nitrogênio foram reduzidos em densidades de braquiária superiores a 15 plantas $m^{-2}$.

Palavras-chave: Urochloa (syn. Brachiaria), densidade de semeadura, integração lavoura-pecuária.

\section{ABSTRACT}

In intercropping competition among species for environmental resources can cripple the system. The amount of interference of one species over another as a result of this competition depends on the species population density which

\begin{abstract}
composed the system. In the search for better understanding these effects it was evaluated the effects of $\boldsymbol{U}$. brizantha densities on forage growth and nutritional efficiency and productivity of maize in intercropping system. The treatments were randomized in blocks with four replications. The DHB 390 RR corn was sown at a spacing of $0.50 \mathrm{~m}$ in the population of 60.000 plants $\mathrm{ha}^{-1}$, with the planting of brachiaria performed manually in rows. Nutritional assessments were performed at 60 after planting the species (DAP) and grain yield of maize and dry weight was measured for brachiaria 160 DAP. The dry matter brachiaria presented quadractricaly behaviour with the increasing planting density. The increased density of $\boldsymbol{U}$. brizantha resulted in a linear reduction of the levels of nitrogen, phosphorus, calcium and magnesium in maize plants, however, without changing the levels of potassium and sulfur. Grain yield was negatively affected in density of more than 15 plants $m^{-2}$ brachiaria. It is concluded that the interference of $\boldsymbol{U}$. brizantha on corn planting simultaneously, reduces the levels of phosphorus, calcium and magnesium independent of density. Grain yield and total nitrogen were reduced by brachiaria densities higher than 15 plants $\mathrm{m}^{-2}$.
\end{abstract}

Key words: Urochloa (syn. Brachiaria), seeding rate, croplivestock integration.

\section{INTRODUÇ̃̃̃O}

A introdução da braquiária nos sistemas de produção de grãos tem sido uma das principais ferramentas utilizadas para a intensificação da exploração de áreas destinadas à agropecuária no Brasil. Uma das técnicas de cultivo consiste no consórcio do milho com a braquiária em semeadura simultânea ou posterior ao plantio da cultura destinada

'Departamento de Ciências Agrárias, Universidade Federal Rural do Semi-Árido (UFERSA), Mossoró, RN, Brasil.

"Departamento de Fitotecnia, Universidade Federal de Viçosa (UFV), 36571000, Viçosa, MG, Brasil. E-mail: gustavogamp@hotmail.com.

*Autor para correspondência.

IIIDepartamento de Ciências Agrárias, Instituto Federal Goiano, Posse, GO, Brasil.

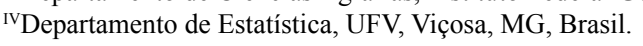


à produção de grãos. Esse consórcio apresenta como vantagens, além da produção de grãos do milho, a formação de palhada para o plantio direto ou a recuperação/reforma de pastagens degradadas (CARVALHO et al., 2005).

$\mathrm{Na}$ implantação do consórcio milhobraquiária, vários arranjos de semeadura podem ser adotados, os quais influenciam diretamente o sucesso desse sistema (FREITAS, 2013). Quando a semeadura da braquiária é realizada simultaneamente à do milho a interferência da forrageira sobre a cultura pode reduzir a produção de grãos e, consequentemente, comprometer a receita utilizada pelo produtor para amortizar o custo da implantação da pastagem (GARCIA et al., 2012).

A interferência é o conjunto de ações resultantes da competição pelos recursos naturais do meio e outras interações entre plantas da comunidade infestante e a cultura, que ocorre em sistemas de cultivos (SILVA et al., 2007). No caso dos cultivos consorciados a interferência interespecífica pode provocar menor crescimento e desenvolvimento das espécies, inviabilizando o sistema. Espera-se que essa interferência seja mais forte quando se estabelece a competição entre espécies que apresentam semelhanças quanto ao nicho ocupado pelas espécies, ou seja, a competição pelos recursos de crescimento seja mais pronunciada (VIDAL, 2010).

Outro fator que afeta a resposta de uma cultura à interferência é a densidade populacional da espécie competidora. Esta característica influencia diretamente na magnitude dos efeitos promovidos pela competição sobre a produtividade final da espécie de interesse. Segundo VIDAL (2010) sob baixas densidades de planta daninha, o impacto de cada infestante no rendimento da cultura é muito acentuado, mas, à medida que aumenta a densidade, a influência das plantas daninhas se sobrepõe e o impacto relativo de cada indivíduo já não é tão evidenciado. Dessa maneira, espera-se que um aumento da densidade de semeadura da braquiaria, cultivada em consórcio com o milho, aumente também o número de plantas da primeira, e consequentemente a competição entre as espécies.

No consórcio do milho com a $\boldsymbol{U}$. decumbens pode ocorrer interferência da forrageira no estado nutricional da cultura e, consequentemente, na produtividade final de grãos (JAKELAITIS et al., 2005a). Segundo SILVA et al. (2007), a intensidade dessa interferência depende das condições do solo e clima, das cultivares utilizadas e do manejo empregado. Todavia, alguns autores (PORTES et al., 2000; JAKELAITIS et al., 2005) indicam que a viabilidade do consórcio milho-braquiária é devido ao diferencial na taxa de crescimento inicial e pelos distintos picos de demandas nutricionais, tornando, dessa forma, possível atender às exigências das diferentes espécies sem exceder a taxa máxima pela qual os nutrientes podem ser supridos pelo ambiente.

Diante do exposto, objetivou-se neste trabalho avaliar os teores de macronutrientes e a produtividade do milho cultivado em consórcio com diferentes densidades de braquiária (Urochloa brizantha Stapf).

\section{MATERIAL E MÉTODOS}

O experimento foi realizado no período de outubro de 2011 a março de 2012 no campo experimental do Aeroporto ( $20^{\circ} 44^{\prime} 37,8^{\prime \prime} \mathrm{S}$ e $42^{\circ} 50^{\prime}$ $40^{\prime}$ W, altitude de $650 \mathrm{~m}$ ), pertencente à Universidade Federal de Viçosa, Viçosa-MG. A área se encontrava em pousio desde o último cultivo de milho na safra de 2010/2011, colhida em março. O clima da região é subtropical úmido com inverno seco e verão quente, de acordo com a classificação de Koppen-Geiger, com temperatura média anual de $21^{\circ} \mathrm{C}$ e precipitação pluviométrica média anual de $1.200 \mathrm{~mm}$. Os dados climáticos coletados na área experimental durante a realização da pesquisa estão apresentados na figura 1 .

Os tratamentos foram constituídos do milho cultivado em consórcio com a Urochloa brizantha, cv. 'Piatã', em sete densidades populacionais $(0,8,9$, $12,14,15,17$ e 23 plantas $\mathrm{m}^{-2}$ ) equivalente ao plantio de $0,1,2,3,4,6,8$ e $10 \mathrm{~kg} \mathrm{ha}^{-1}$ (Valor Cultural=76\%), dispostos em delineamento em blocos casualizados, com quatro repetições. Cada unidade experimental apresentou 10 linhas de milho de $6 \mathrm{~m}$ de comprimento, espaçadas de $0,50 \mathrm{~m}$, sendo que a área útil constituiuse das seis linhas centrais, excluindo $1 \mathrm{~m}$ de cada borda, totalizando $12 \mathrm{~m}^{2}(3 \times 4 \mathrm{~m})$.

Para o preparo da área experimental, foi realizada a dessecação da vegetação aos quinze dias antes do plantio por meio da aplicação da mistura em tanque dos herbicidas glyphosate $\left(1.080 \mathrm{~g} \mathrm{ha}^{-1}\right)+2,4-$ D (540 $\left.\mathrm{g} \mathrm{ha}^{-1}\right)$. O milho (DKB $390 \mathrm{RR}$ ) foi semeado com o uso de uma semeadora múltipla Semeato SHM 11/13, adotando-se uma população de 60.000 plantas por hectare. No mesmo dia, semeou-se a $\boldsymbol{U}$. brizantha manualmente na linha de plantio do milho, respeitando a quantidade estipulada para cada tratamento.

A análise química e granulométrica do solo da área experimental encontra-se descrita na tabela 1. O solo foi classificado como Argissolo Vermelho-Amarelo, de textura argilosa. A adubação 


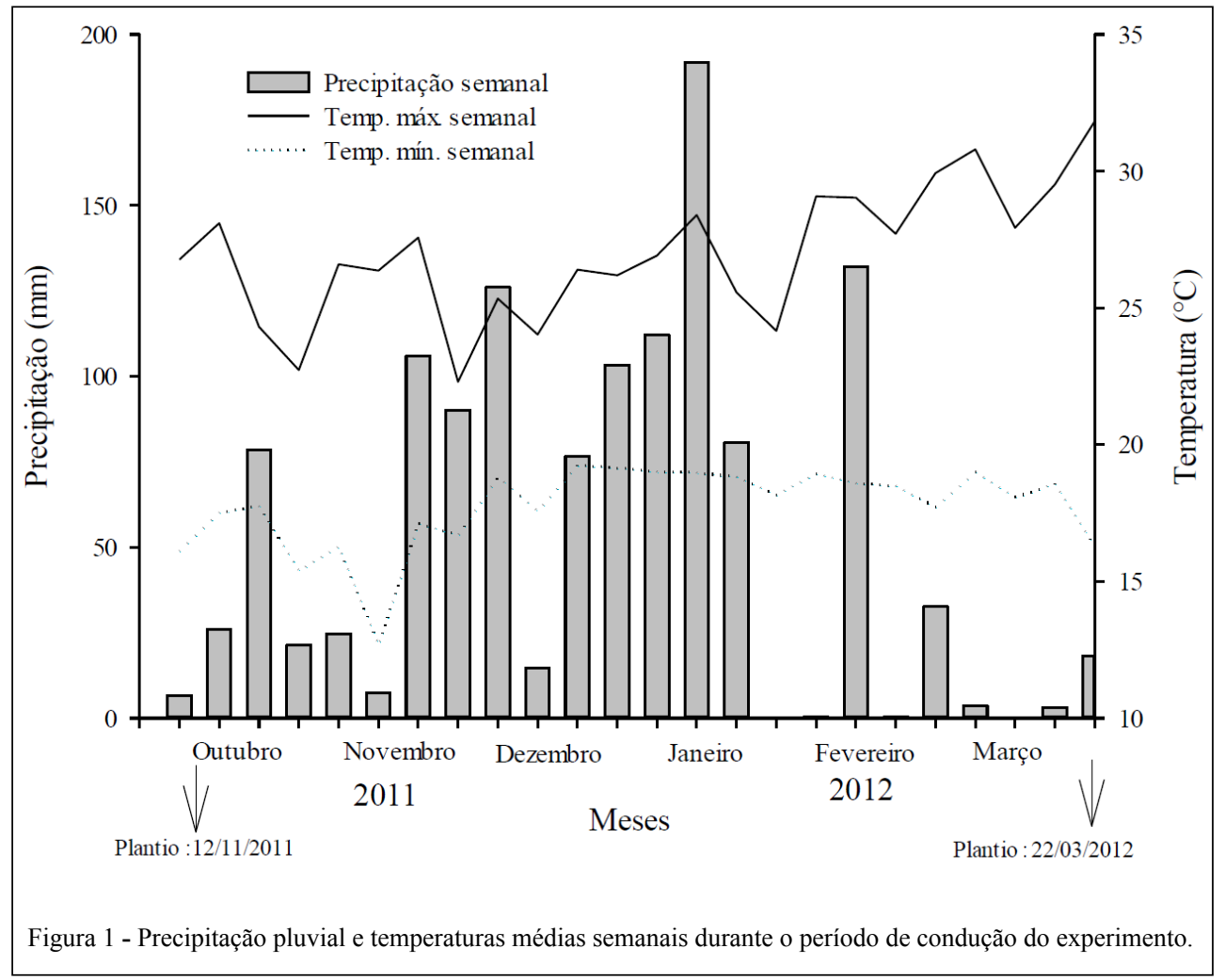

de plantio foi realizada com a aplicação de 20, 120 e $90 \mathrm{~kg} \mathrm{ha}^{-1}$ de $\mathrm{N}, \mathrm{P}_{2} \mathrm{O}_{5}$ e $\mathrm{K}_{2} 0$, respectivamente, distribuídos na linha de plantio do milho conforme recomendado por ALVAREZ et al. (1999). A adubação de cobertura constou da aplicação de $300 \mathrm{~kg}$ $\mathrm{ha}^{-1}$ de $\mathrm{N}$ na forma de ureia, aplicada quando o milho apresentava seis folhas completamente expandidas.

$\mathrm{O}$ controle das plantas daninhas dicotiledôneas em pós-emergência foi realizado com a aplicação do herbicida atrazine + óleo na dose de $1.500 \mathrm{~g} \mathrm{ha}^{-1}$ aos 30 dias após o plantio (DAP) do milho. Na testemunha em monocultivo, o controle da braquiária e demais plantas daninhas foi feito por meio de capinas manuais, quando necessário.

Aos 60 DAP determinou-se a densidade de braquiária através da avaliação do número de plantas presente em 4 linhas da área útil, cada uma com 2 metros lineares $\left(4 \mathrm{~m}^{-2}\right)$. No mesmo dia coletouse a folha oposta e abaixo da espiga superior de dez plantas de milho (MALAVOLTA et al., 1997) por unidade experimental, para a avaliação do teor de nitrogênio $(\mathrm{N})$, fósforo $(\mathrm{P})$, potássio $(\mathrm{K})$, cálcio $(\mathrm{Ca})$, magnésio $(\mathrm{Mg})$ e enxofre $(\mathrm{S})$.

As folhas coletadas foram secas em estufa de circulação forçada de ar $\left(70 \pm 2^{\circ} \mathrm{C}\right)$ até atingir massa constante e posteriormente moído $(<1,00 \mathrm{~mm})$ e submetidos a análise do material vegetal. $\mathrm{O} N$ foi determinado por destilação Kjeldahl, após digestão sulfúrica do material vegetal (TEDESCO et al., 1995). Foi realizada a digestão nitroperclórica do material vegetal para determinação dos teores de $\mathrm{P}$ por colorimetria (BRAGA \& DE FELIPO, 1974), de $\mathrm{K}$ por fotômetro de chama, de $\mathrm{Ca}$ e $\mathrm{Mg}$ por espectrofotometria de absorção atômica (TEDESCO

Tabela 1 - Características físico-químicas da camada de 0-20cm do solo antes da instalação do experimento.

\begin{tabular}{|c|c|c|c|c|c|c|c|c|c|c|c|c|}
\hline $\mathrm{pH}$ & $\mathrm{P}$ & $\mathrm{K}$ & $\mathrm{Ca}$ & $\mathrm{Mg}$ & $\mathrm{Al}$ & $\mathrm{H}+\mathrm{Al}$ & SB & $(\mathrm{t})$ & $(\mathrm{T})$ & V & $\mathrm{m}$ & $\mathrm{MO}$ \\
\hline $\mathrm{H}_{2} \mathrm{O}$ & -------M & $-3---$ & -------- & $-\cdots$ & - & $---\mathrm{cmol}_{\mathrm{c}}$ & $\begin{array}{c}----- \\
-\cdots+1\end{array}$ & ------ & --------- & $\begin{array}{ll}----\cdot \\
\end{array}$ & ------ & dag $\mathrm{kg}^{-1}$ \\
\hline 5,6 & 5,9 & 64 & 2,0 & 0,8 & 0,3 & 3,3 & 2,96 & 2,96 & 6,26 & 47 & 0 & 2,6 \\
\hline \multicolumn{5}{|c|}{ Granulometria (\%) } & \multicolumn{3}{|c|}{ Argila $=43$} & \multicolumn{2}{|c|}{ Silte $=14$} & \multicolumn{3}{|c|}{ Areia $=43$} \\
\hline
\end{tabular}

Análises realizadas no Laboratório de Análises de Solo Viçosa, segundo a metodologia da Empresa Brasileira de Pesquisa Agropecuária EMBRAPA (1997). 
et al., 1995) e de S por turbidimetria do sulfato (JACKSON, 1958).

Aos 160 DAP procedeu-se à colheita manual do milho na área útil das unidades experimentais, sendo posteriormente, determinada a produtividade de grãos corrigida para $13 \%$ de umidade. Na mesma ocasião, foi avaliada a matéria seca da parte aérea das plantas de braquiária, quando apresentava de oito a dez folhas ou afilhos.

Os dados foram submetidos à análise de variância pelo teste $\mathrm{F}$ e análise de regressão, sendo a escolha do modelo baseada na significância dos coeficientes $(\mathrm{P}<0,05)$, no coeficiente de determinação e no comportamento biológico do fenômeno.

\section{RESULTADOS E DISCUSSÃO}

O teor de nitrogênio $(\mathrm{N})$ das folhas de milho apresentou comportamento quadrático em relação à densidade de plantas de braquiária (Figura 2a). O maior teor de $\mathrm{N}(3,01)$ foi observado na densidade de $9,5 \mathrm{pl}$ $\mathrm{m}^{-2}$ de braquiária, com incremento de $6 \%$. Apesar dos valores diferenciados, o teor foliar de $\mathrm{N}$ em todos os tratamentos ficou dentro da faixa adequada de 2,75 a $3,25 \mathrm{dag} \mathrm{kg}^{-1}$ para a cultura no milho (COELHO et al., 2006), exceto para densidades da forrageira acima de 22 plantas $\mathrm{m}^{-2}$.

De acordo com NASCIMENTO et al. (2010), o aumento da disponibilidade de nitrogênio, principalmente através da adubação mineral, é acompanhada de resposta positiva dos teores de $\mathrm{N}$ na folha. Os resultados observados nesta pesquisa indicam que em virtude da grande exigência de $\mathrm{N}$ por ambas as espécies, quando consorciadas simultaneamente, pode haver competição pelo nutriente (BORGHI \& CRUSCIOL, 2007) e que este fato pode ser agravado pelo maior número de plantas da forrageira. Alguns autores (JAKELAITIS et al., 2005; TRIGUEIRO et al., 2007; PETTER et al., 2011) indicam a aplicação
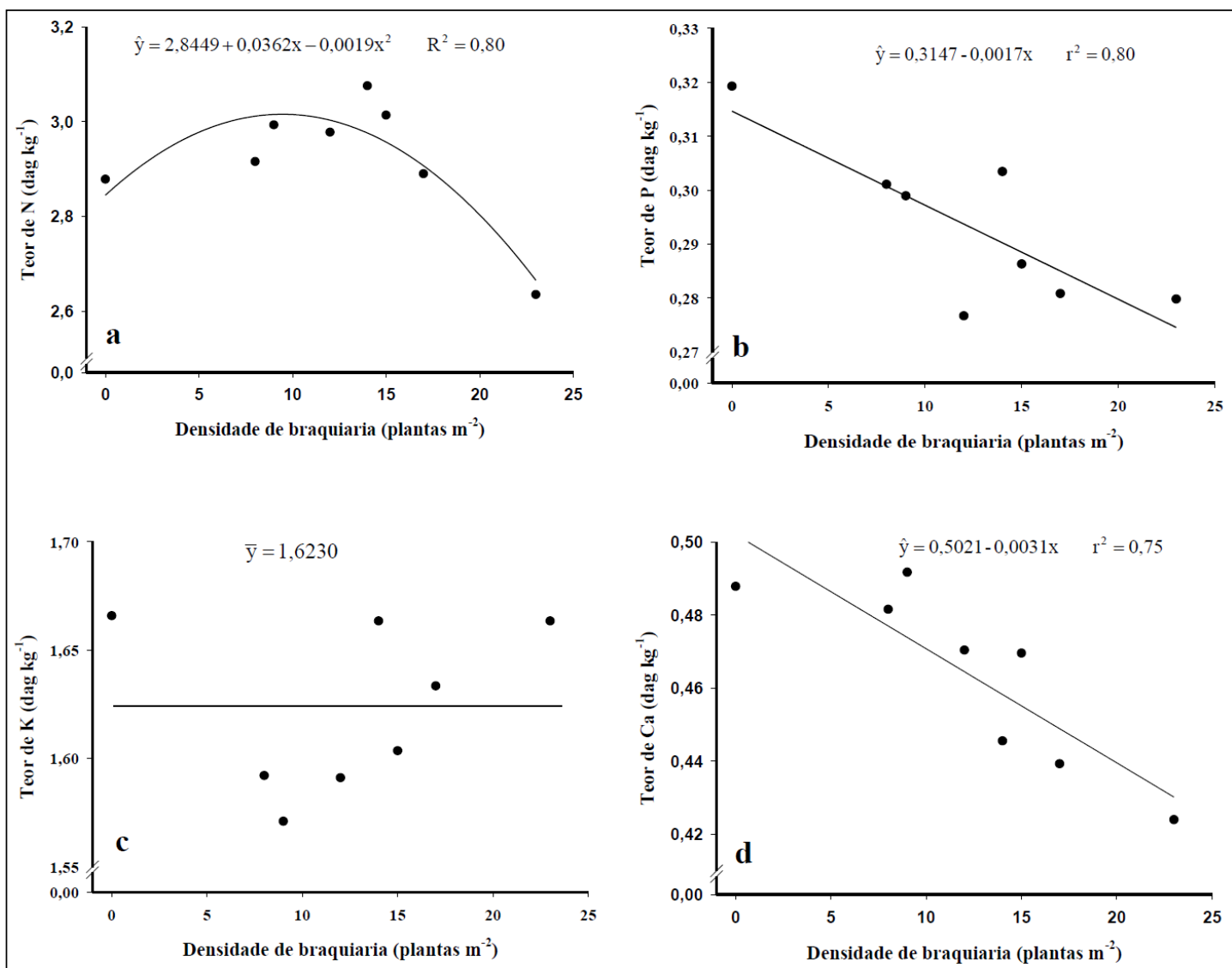

Figura 2 - Teores de nitrogênio $(\mathrm{N})(\mathrm{a})$, fósforo $(\mathrm{P})(\mathrm{b})$, potássio $(\mathrm{K})$ (c) e cálcio (Ca) (d) em plantas de milho, cultivadas no espaçamento de $0,50 \mathrm{~m}$ e população de 60000 plantas ha $^{-1}$, em consórcio com Urochloa brizantha, em diferentes densidades.

Ciência Rural, v.45, n.8, ago, 2015. 
do herbicida nicosulfuron em subdosagem como forma de minimizar os efeitos competitivos da braquiária com a cultura durante o período crítico de prevenção da interferência do milho.

$\mathrm{O}$ aumento da densidade de braquiária reduziu linearmente o teor de fósforo $(\mathrm{P})$ nas folhas de milho, sendo que o incremento de cada planta forrageira promove redução de $0,0017 \mathrm{dag}_{\mathrm{kg}^{-1}} \mathrm{da}$ variável (Figura $2 \mathrm{~b}$ ). $\mathrm{O}$ crescimento da $\boldsymbol{U}$. brizantha é caracterizado por um maior incremento inicial do sistema radicular, visando a melhor fixação da planta no solo e rápido acúmulo de nutrientes pelas raízes, o que favorece na competição pelo fósforo do solo com as culturas (BIANCO et al., 2005). Dessa maneira, espera-se que quanto maior o número de plantas de braquiária próximos à planta de milho, menor será o conteúdo de fósforo nas folhas da cultura.

$\mathrm{O}$ teor de potássio $(\mathrm{K})$ não foi afetado pelo aumento da densidade da braquiária, enquanto, o teor de cálcio $(\mathrm{Ca})$ foi reduzido linearmente (Figura 2c e $2 \mathrm{~d}$ ). $\mathrm{O}$ aumento de uma unidade (plantas $\mathrm{m}^{-2}$ ) de braquiária reduziu em $0,0031 \mathrm{dag}_{\mathrm{kg}^{-1}} \mathrm{o}$ teor de Ca nas folhas do milho. A baixa capacidade competitiva do milho pelo cálcio já foi identificada por outros autores e pode estar relacionada ao menor crescimento do milho na presença da braquiária (FREITAS, 2013; CURY et al., 2012). GIMENES et al. (2008) relataram que maiores densidades de forrageira possibilitaram grande exploração do solo em superfície e volume e, consequentemente, intensificaram os efeitos competitivos sobre as demais plantas do sistema.

Semelhante ao observado para o $\mathrm{Ca}$, o teor de magnésio $(\mathrm{Mg})$ nas folhas de milho foi reduzido linearmente em função da densidade de braquiária (Figura 3a). Todavia, não foram constatadas alterações no teor de enxofre $(\mathrm{S})$ nas folhas de milho (Figura $3 b$ ). Esses resultados indicam que a competição das plantas pelo $\mathrm{S}$ no solo pode não ser tão limitante. Resultados semelhantes já foram observados por JAKELAITIS et al. (2005) e COSTA et al. (2012) e podem estar relacionado ao uso de adubos a base de enxofre e, consequentemente, o aumento de nutriente no solo.

Para a produtividade de grãos do milho, foi ajustada a equação sigmoidal para o estudo do comportamento da variável em função da densidade de braquiária (Figura 3). Admitindose uma perda de $5 \%$ da produtividade de grãos

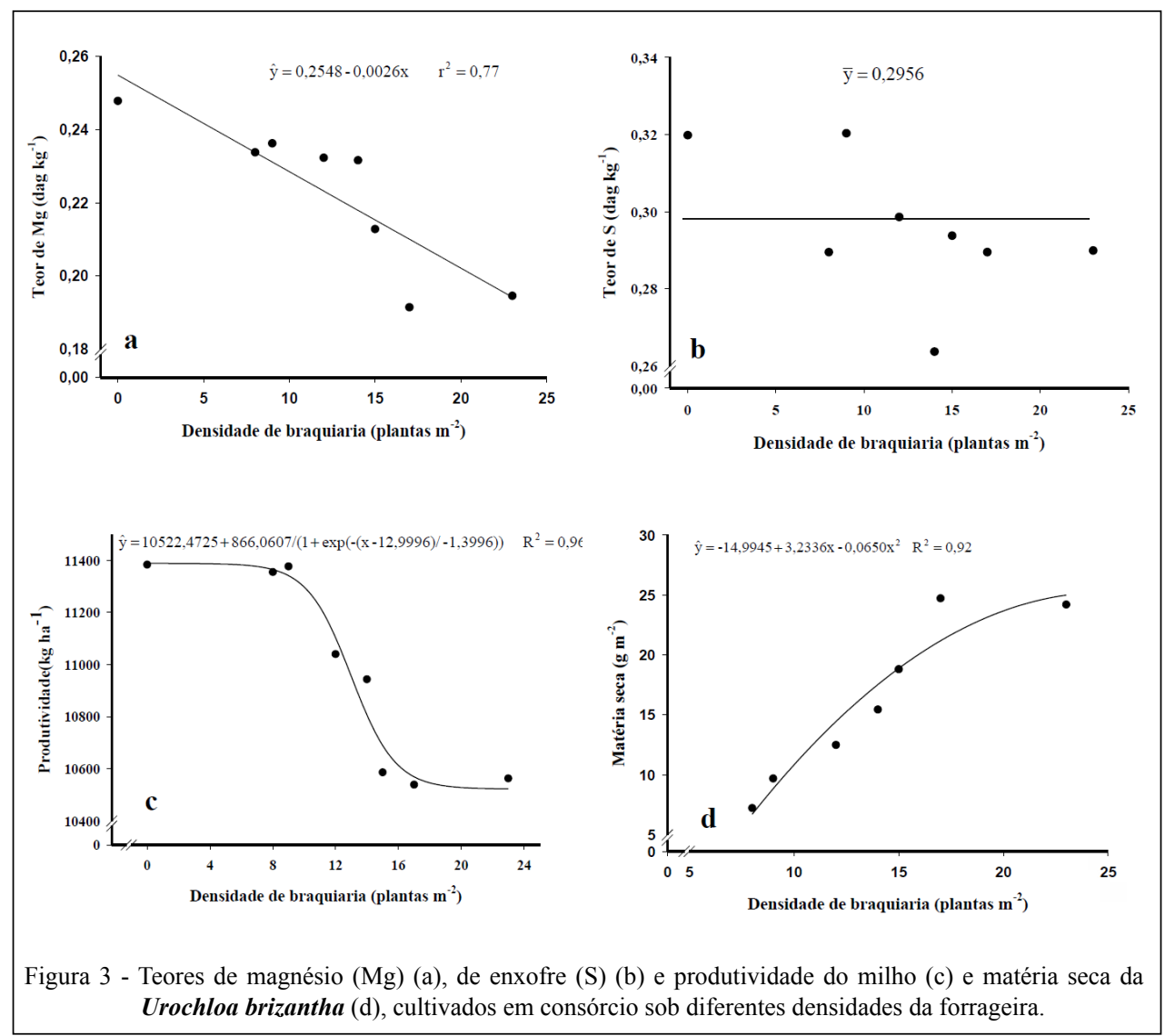

Ciência Rural, v.45, n.8, ago, 2015. 
como o máximo tolerável de perdas (HALL et al., 1992), é possível observar pelo modelo ajustado, que densidades acima de 14 plantas $\mathrm{m}^{-2}$ promovem reduções significativas da variável. Possivelmente, o plantio da forrageira na linha do milho favorece o crescimento da braquiária pela proximidade desta com o adubo depositado na linha, visando à nutrição do milho. Nesse sentido, a interferência da braquiária sobre o milho é aumentada, causando efeito negativo sobre a cultura.

Em densidades acima de 17 plantas $\mathrm{m}^{-2}$ da $\boldsymbol{U}$. brizantha, a redução da produtividade de grãos foi aproximadamente $8 \%$ ou $866 \mathrm{~kg} \mathrm{ha}^{-1}$. Esse valor pode ser considerado baixo, visto que pode ser compensado pela maior produção da braquiaria, caso o crescimento por área seja compensado pelo aumento no número de plantas. Esses resultados corroboram o descrito por VIDAL (2010) sobre o impacto do aumento da densidade da planta considerada daninha sobre a produção da cultura, já que o aumento do número de plantas da infestante é acompanhado do decréscimo da produtividade até o momento em que a própria competição interespecífica entre as plantas daninhas se sobressai.

Constatou-se comportamento quadrático da matéria seca da parte aérea da braquiária com o aumento da densidade de plantio (Figura 3d). Segundo PEQUENO et al. (2006), a braquiária atinge maiores produções de matéria seca quando o plantio é realizado simultaneamente ao do milho. Todavia, a produção de matéria seca observada no presente trabalho, foi maior do que a constatada por PORTES et al. (2000), sendo que esses autores relaram redução superior a $80 \%$ da biomassa de forrageira do consórcio em comparação ao cultivo solteiro.

O comportamento do milho, quando em consórcio com a braquiária, é muito influenciado pela velocidade de estabelecimento da forrageira e do aumento da competição por água, luz e nutrientes, o que pode prejudicar o desenvolvimento e consequentemente a produtividade de grãos da cultura (PARIZ et al., 2011). No presente trabalho, a emergência da $\boldsymbol{U}$. brizantha foi observada junto com a do milho, e esse fato pode ter contribuído para a maior capacidade competitiva com ele.

O consórcio do milho com a braquiária, em condições semelhantes ao deste trabalho, mostrase viável, pois, mesmo em maiores densidades da forrageira, a redução de produtividade de grãos não ultrapassou a $10 \%$ e pode ser compensada pela produção de forragem no período seco, bem como do seu uso para palhada no plantio direto.

\section{CONCLUSÃO}

O aumento da população de braquiária afeta negativamente os teores de nutrientes da folha de milho. O consórcio é viável, pois a redução da produtividade não foi superior a $8 \%$, mesmo em maiores densidades de plantio e pode ser compensada pela maior produção da forrageira.

\section{AGRADECIMENTOS}

Ao Conselho Nacional de Desenvolvimento Científico e Tecnológico (CNPq), à Coordenação de Aperfeiçoamento de Pessoal de Nível Superior (CAPES) e à Fundação de Amparo a Pesquisa do Estado de Minas Gerais (FAPEMIG) pelo apoio financeiro.

\section{REFERÊNCIAS}

ALVAREZ, V.H.V. et al. Recomendação para o uso de corretivos e fertilizantes em Minas Gerais: 5. Aproximação. Viçosa: Comissão de Fertilidade do Solo do Estado de Minas Gerais, 1999. 322p.

BIANCO, S. et al. Crescimento e nutrição mineral de capimbraquiária. Planta Daninha, v.23, n.3, p.423-428, 2005. Disponível em: <http://www.scielo.br/pdf/pd/v23n3/a05v23n3.pdf $>$. Acesso em: 4 nov. 2014. doi: 10.1590/S0100-83582005000300005.

BORGHI, E.; CRUSCIOL, C.A.C. Produtividade de milho, espaçamento e modalidade de consorciação com Brachiaria brizantha em sistema plantio direto. Pesquisa Agropecuária Brasileira, v.42, n.2, p.163-171, 2007. Disponível em: <http:// www.scielo.br/pdf/pab/v42n2/04.pdf >. Acesso em: 4 fev. 2014. doi: 10.1590/S0100-204X2007000200004.

CARVALHO, G.G.P. et al. Integração agricultura-pecuária: um enfoque sobre cobertura vegetal permanente. Revista Electrónica de Veterinaria, v.6, n.8, p.1-19, 2005. Disponível em: <http:// www.veterinaria.org/revistas/redvet/n080805/080507.pdf $>$. Acesso em: 8 fev. 2014.

COSTA, N.R. et al. Adubação nitrogenada no consórcio de milho com duas espécies de braquiária em sistema plantio direto. Pesquisa Agropecuária Brasileira, v.47, n.8, p.1038-1047, 2012. Disponível em: $<$ http://www.scielo.br/scielo.php?script $=$ sci arttext\&pid=S0100-204X2012000800003\&lang=pt $>$. Acesso em: 14 mar. 2014. doi: 10.1590/S0100-204X2012000800003.

CURY, J.P. et al. Acúmulo e partição de nutrientes de cultivares de milho em competição com plantas daninhas. Planta Daninha, v.30, n.2, p.287-296, 2012. Disponível em: <http://www.scielo. $\mathrm{br} / \mathrm{pdf} / \mathrm{pd} / \mathrm{v} 30 \mathrm{n} 2 / \mathrm{v} 30 \mathrm{n} 2 \mathrm{a} 07 . \mathrm{pdf}>$. Acesso em: 14 mar. 2014. doi: 10.1590/S0100-83582012000200007.

FREITAS, M.A.M. Impacto do consórcio milho-braquiária no crescimento, características nutricionais e fisiológicas do milho e na atividade da microbiota do solo. 2013. 49f. Tese (Doutorado em Fitotecnia) - Curso de Pós-graduação em Fitotecnia, Universidade Federal de Viçosa, MG.

GARCIA, C.M.P. et al. Análise econômica da produtividade de grãos de milho consorciado com forrageiras dos gêneros 
Brachiaria e Panicum em sistema plantio direto. Revista Ceres, v.59, n.2, p.157-163, 2012. Disponível em: <http://www. scielo.br/pdf/rceres/v59n2/02.pdf >. Acesso em: 5 mar. 2014. doi: 10.1590/S0034-737X2012000200002.

GIMENES, M.J. et al. Interferência de espécies forrageiras em consórcio com a cultura do milho. Revista da Faculdade de Zootecnia, Veterinária e Agronomia, v.15, n.2, p.61-76, 2008. Disponível em: <http://revistaseletronicas.pucrs.br/ojs/index.php/ fzva/article/view/2804/3896>. Acesso em: 5 mar. 2014.

JAKELAITIS, A. et al. Influência de herbicidas e de sistemas de semeadura de Brachiaria brizantha consorciada com milho Planta Daninha, v.2, n.1, p.59-67, 2005a. Disponível em: <http:/ www.scielo.br/pdf/pd/v23n1/23929.pdf>. Acesso em: 5 mar. 2014 doi: 10.1590/S0100-83582005000100008.

JAKELAITIS, A. et al. Efeitos do nitrogênio sobre o milho cultivado em consórcio com Brachiaria brizantha. Acta Scientiarum. Agronomy, v.27, n.1, p.39-46, 2005b. Disponível em: <http://periodicos.uem.br/ojs/index.php/ActaSciAgron/article/ viewFile/1916/1230>. Acesso em: 8 mar. 2014. doi: 10.4025/ actasciagron.v27il.1916

JACKSON, M.L. Soil chemical analysis. New Jersey: Prentice Hall, 1958. 498p.

NASCIMENTO, F.M. et al. Diagnose foliar em plantas de milho em sistema de semeadura direta em função de doses e épocas de aplicação de nitrogênio. Revista Brasileira de Tecnologia Aplicada nas Ciências Agrárias, v.5, n.1, p.67-86, 2012 Disponível em: <http://revistas.unicentro.br/index.php/repaa/ article/viewFile/PAeT.V5.N1.04/1688>. Acesso em: 5 mar. 2014. doi: 10.5777/PAeT.V5.N1.04.

PARIZ, C.M. et al. Produtividade de grãos de milho e massa seca de braquiárias em consórcio no sistema de integração lavoura pecuária. Ciência Rural, v.41, n.2, p.875-882, 2011. Disponível em: <http:/www.scielo.br/pdf/cr/v41n5/a942cr2241.pdf > . Acesso em: 5 mar. 2014. doi: 10.1590/S0103-84782011000500023.
PEQUENO, D.N.L. et al. Efeito da época de semeadura da Brachiaria brizantha em consórcio com o milho, sobre caracteres agronômicos da cultura anual e da forrageira, em Gurupi, estado do Tocantins. Amazônia: Ciência e Desenvolvimento, v.2, n.3, p.127133, 2006. Disponível em: <http://siteantigo.bancoamazonia.com. br/bancoamazonia2/Revista/edicao_03/Efeito_Epoca_Semeadur. pdf>. Acesso em: 5 mar. 2014.

PETTER, F.A. et al. Seletividade de herbicidas à cultura do milho e ao capim-braquiária cultivadas no sistema de integração lavoura-pecuária. Semina: Ciências Agrárias, v.32, n.3, p.855-864, 2011. Disponível em: <http://www. uel.br/revistas/uel/index.php/semagrarias/article/view/1679 0359.2011v32n3p855/9042>. Acesso em: 5 mar. 2014. doi: $10.5433 / 1679-0359.2011 v 32 \mathrm{n} 3 \mathrm{p} 855$.

PORTES, T.A. et al. Análise do crescimento de uma cultivar de braquiária em cultivo solteiro e consorciado com cereais. Pesquisa Agropecuária Brasileira, v.35, n.7, p.13491358, 2000. Disponível em: <http://www.scielo.br/pdf/pab/ v35n7/1349.pdf $>$. Acesso em: 5 mar. 2014. doi: 10.1590/S0100204X2000000700009.

SILVA, A.A. et al. Herbicidas: classificação e mecanismo de ação. In: SILVA, A.A.; SILVA, J.F. (Eds.). Tópicos em manejo de plantas daninhas. Viçosa, MG: Universidade Federal de Viçosa, 2007. p. $83-148$

TEDESCO, M.J. et al. Análises de solo, plantas e outros materiais. 2.ed. Porto Alegre: Universidade Federal do Rio Grande do Sul, 1995. 174p

TRIGUEIRO, L.R.C. et al. Seletividade de herbicidas aplicados em pós-emergência sobre capim-colonião e efeito na qualidade das sementes. Planta Daninha, v.25, n.2,p.341-349, 2007. Disponível em: <http://www.scielo.br/pdf/pd/v25n2/a14v25n2.pdf >. Acesso em: 5 mar. 2014. doi: 10.1590/S0100-83582007000200014.

VIDAL, R.A. Interação negativa entre plantas: inicialismo, alelopatia e competição. Porto Alegre-RS: UFRGS, 2010. 132p. 